\title{
PHYSICAL MODELLING OF MELT DEGASSING IN THE REFINING LADLE
}

\author{
Josef WALEK, Karel MICHALEK, Jana SVIŽELOVÁ, Jiří ČARVAŠ
}

VSB - Technical University of Ostrava, Ostrava, Czech Republic, EU, josef.walek@vsb.cz

https://doi.org/10.37904/metal.2019.960

\begin{abstract}
The paper describes the use of physical modelling to study the degassing of aluminum melts in the refining ladle by inert gas blowing. The technology of blowing inert gas into the ladle through a rotating impeller is the most common method in operating conditions to reduce the unwanted phases content in molten aluminum, e.g. hydrogen. The high efficiency of this process is related to the creation of fine bubbles with a high interphase surface, their equal distribution into the whole volume of the refining ladle and with relatively long period of its effect in the melt. The presented paper is focused on the evaluation of laboratory experiments obtained using the physical modelling method; special attention is focused on the assessment of relevant parameters for the degassing process - flow rate of inert gas, rotary impeller speeds and impeller variant.
\end{abstract}

Keywords: Physical modelling, refining ladle, inert gas blowing, degassing of the melt, impeller

\section{INTRODUCTION}

Optimisation of the degassing process is difficult under operating conditions. Therefore, in laboratory conditions, so-called modelling is used, where the original work is replaced by the model. The technology of modelling is divided to two basic methods. In numerical modelling, the process is replaced by a mathematical model formed of a system of partial differential equations. In the case of physical modelling, there is a method, in which the real system is replaced by a tangible physical model, which is as close as possible to the behaviour of the real system. In this method, both the work and the model have the same physical substance. One of the advantages of physical modelling is the possibility of visual monitoring and evaluating of the process under review. The results achieved on the model can predict the real system behaviour. The combination of physical and numerical modelling is an optimal model research variant [1].

\section{EXPERIMENTAL CONDITIONS}

Physical modelling of degassing the aluminum melt by inert gas blowing is quite widely used [2]. In the case of physical modelling, the aluminum melt is substituted by water. The water is used due to its low cost, good availability and especially because it has similar physical properties as liquid aluminum. A comparison of the basic parameters of aluminum and water is shown in Table 1.

Laboratory experiments were conducted in accordance with the theory of similarity between the model and the work, based on the identity of Froude's criterion. It is necessary to observe in particular geometrical similarity of the work and its model, and dynamic similarity of fluid flow in work and its model.

Table 1 Comparison of basic physical parameters of the aluminum melt and water [1]

\begin{tabular}{|c|c|c|c|c|}
\hline Parameter & Symbol & Unit & Aluminum & Water \\
\hline Melting temperature & $T$ & $\mathrm{~K}$ & 1023 & 293 \\
\hline Density & $\rho$ & $\mathrm{kg} \cdot \mathrm{m}^{-3}$ & 2345 & 998.5 \\
\hline Dynamic viscosity & $\eta$ & $\mathrm{kg} \cdot \mathrm{m}^{-1} \cdot \mathrm{s}^{-1}$ & 0.00120 & 0.00101 \\
\hline Kinematic viscosity & $v$ & $\mathrm{~m}^{2} \cdot \mathrm{s}^{-1}$ & $0.51 \cdot 10^{-6}$ & $1.012 \cdot 10^{-6}$ \\
\hline Surface tension & $\sigma$ & $\mathrm{N} \cdot \mathrm{m}^{-1}$ & 0.680 & 0.072 \\
\hline
\end{tabular}


Experiments investigating degassing the metal melt with inert gas in refining ladle were performed in the Laboratory of Physical and Numerical Modelling at the Department of Metallurgy and Foundry, FMT (Faculty of Materials Science and Technology), VŠB - TU Ostrava. The physical model was made of organic glass (plexiglass) at a 1:1 geometric scale for a pilot plant of warm refining ladle model. Also, two graphite baffles for suppressing excessive surface ripple and vortex formation were included in the physical modelling. Figure 1 shows a physical model assembly and Figure 2 shows two variants of the impellers used.
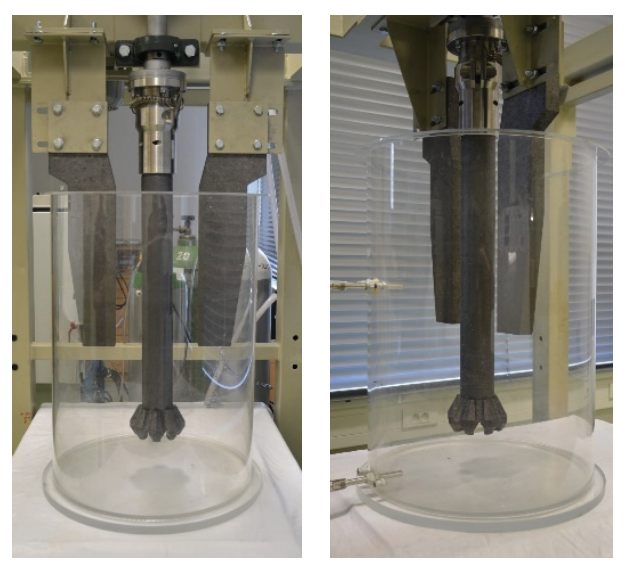

Figure 1 Physical model assembly: refining ladle, impeller, $2 x$ baffles and measuring probes

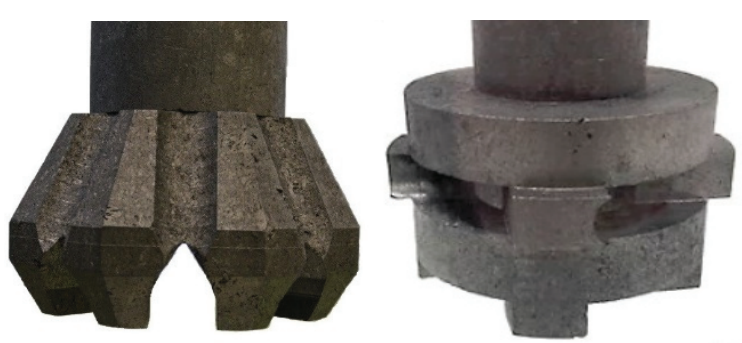

Figure 2 Detail of the impeller head for physical modelling: variant J8 (left), variant F2A

The change of the impeller immersion was solved by a hydraulically controlled platform on which physical model of the ladle was placed. Rotary impeller speeds (revolutions per minute; rpm) were resolved by using an asynchronous motor, powered through an inverter. Mass flowmeters and needle valves were used to measure and regulate the flow of gases (oxygen and argon).

The decrease of hydrogen content in the aluminum melt during inert gas refining was simulated in the physical model by a decrease in the dissolved oxygen content in the model liquid (water). Before each experiment, water was saturated with gaseous oxygen to the value of $23 \mathrm{ppm}\left(23 \mathrm{mg} \mathrm{O} \cdot \mathrm{l}^{-1}\right.$ of water) through the rotating impeller. The actual experiment was started with exact rotary impeller speed and flow rate of argon. For oxygen content measuring, two optical fluorescence probes were used, each of them was placed in two different positions of the ladle model. Figure 3 shows the basic dimensional data of the physical model, including the location of the measuring probes.

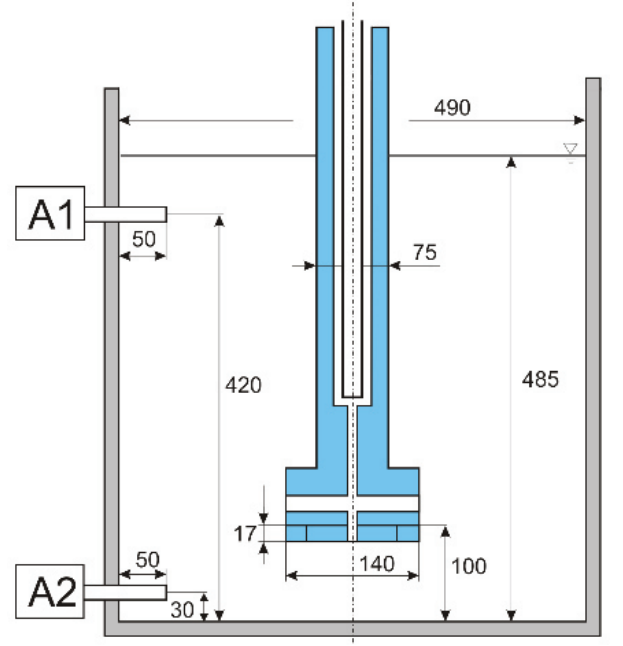

Figure 3 Basic dimensional data of physical model 


\section{EXPERIMENTS AND THEIR EVALUATION}

The main aim of physical modelling was to achieve insight into the effect of relevant parameters (see Table 2) on the removal of dissolved oxygen during refining. The research concentrated on rotary impeller speeds, inert gas flow and impeller variant.

Table 2 Overview of the experiments performed

\begin{tabular}{|c|c|c|c|c|}
\hline Variant of impeller & J8 & J8 & J8 & F2A \\
\hline & & 250 & & 250 \\
Rotary impeller speeds $(\mathrm{rpm})$ & 350 & 350 & 350 & 350 \\
& 500 & 500 & 500 & 500 \\
& 650 & 650 & 650 & \\
\hline Flow rate of $\operatorname{Ar}\left(\mathrm{Nl} \cdot \mathrm{min}^{-1}\right)$ & 5.0 & 10.0 & 15.0 & 10.0 \\
\hline
\end{tabular}

The results of individual experiments were evaluated and processed into graphs, which characterise the time dependence of the course of the reduction of oxygen concentration during refining with inert gas. Due to the relatively small volume and high processability to homogenize the bath, the data from both probes (A1 - upper probe, A2 - lower probe) was almost identical. It can be therefore stated that the decrease in oxygen concentration has the same character in both parts, the lower and upper part of the refining ladle. Therefore, data from the lower probe A2 were used for evaluation.

The most important parameters that have a significant effect on the refining process (dewatering) include the rotary impeller speeds and the flow rate of argon fed to the impeller. From the graphs shown above (see Figure 4), a significant effect of increased rotary impeller speeds on the oxygen content reduction process can be demonstrated. The co-decision factor is also the flow rate of inert gas. At low flow rates of inert gas of $5 \mathrm{Nl} \cdot \mathrm{min}^{-1}$ (see Figure $4 \mathrm{a}$ ), the process of reducing dissolved oxygen is slow and the oxygen concentration is not reduced to $0 \mathrm{ppm}$. At higher flow rates of inert gas of $15 \mathrm{Nl} \cdot \mathrm{min}^{-1}$ (see Figure $4 \mathrm{c}$ ) a relatively low rotary speeds increase from $250 \mathrm{rpm}$ to $350 \mathrm{rpm}$ leads to an increase in the slope of the oxygen concentration curve and hence even to a sharp time decrease. We can also assume that increasing the rotary speed above 650 rpm will no longer have a great positive effect.

The results shown above can also be interpreted as the effect of the flow rate of inert gas at constant rotary speeds, when the flow rate of argon is influenced by 5,10 a $15 \mathrm{Nl} \cdot \mathrm{min}^{-1}$ at gradually increasing rotary speeds of 350, 500 and $650 \mathrm{rpm}$ (see Figure 5). Increasing the flow rate of inert gas has a very similar effect to increasing the rotary impeller speeds. By increasing the volume of inert gas is the melt, the reaction surface of the bubbles of the inert gas is also increased, resulting in an increase in the efficiency of the oxygen decrease process. Another finding that we can observe in all graphs is the sharp increase in process efficiency with a flow rate increase from $5 \mathrm{NI} \cdot \mathrm{min}^{-1}$ to $10 \mathrm{NI} \cdot \mathrm{min}^{-1}$. Another increase of $5 \mathrm{Nl} \cdot \mathrm{min}^{-1}$ to the final $15 \mathrm{NI} \cdot \mathrm{min}^{-1}$ no longer has the same effect and we can therefore assume that further increases will not have a significant effect on efficiency.

The impeller variant can have a significant effect on the refining process as its shape and design can generate a completely different degree of turbulence in the refining ladle at the same rotary speeds and volume flow. The aim of the experimental study was to compare the variant of the $\mathrm{J} 8$ impeller with the previously verified F2A impeller [3]. Figure 6 shows the comparison of results obtained with both impellers at different rotary speeds and at a constant flow rate of inert gas of $10 \mathrm{Nl} \cdot \mathrm{min}^{-1}$, constant distance from the bottom $100 \mathrm{~mm}$ and with the use of two baffles. It can be seen from Figure 6 that the refining efficiency at the rotary speeds of 250 rpm is virtually identical for both impellers. At $350 \mathrm{rpm}$, it was found that the use of the F2A impeller leads to an apparently faster decrease in dissolved oxygen content during refining, at $500 \mathrm{rpm}$ the efficiency of both impellers differs less. 


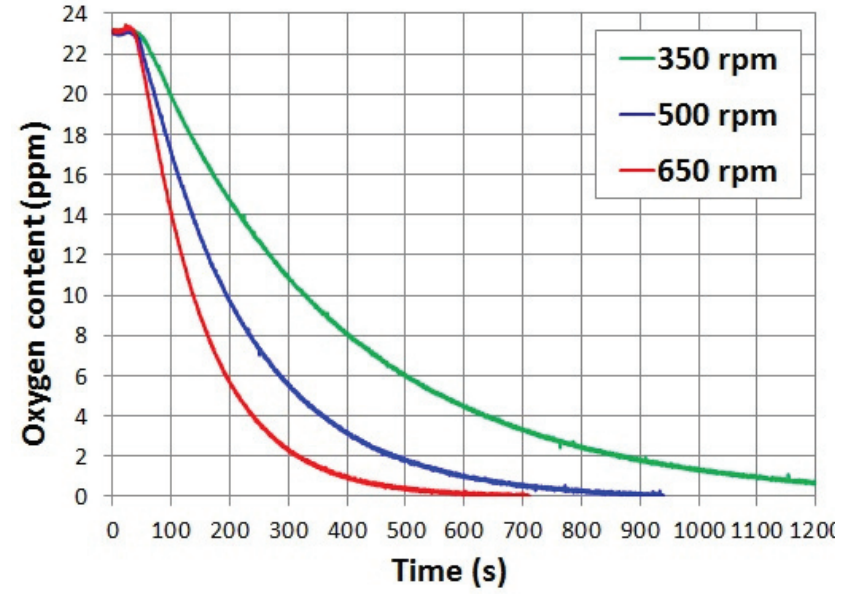

a) flow rate of $\mathrm{Ar}: 5.0 \mathrm{Nl} \cdot \mathrm{min}^{-1}$

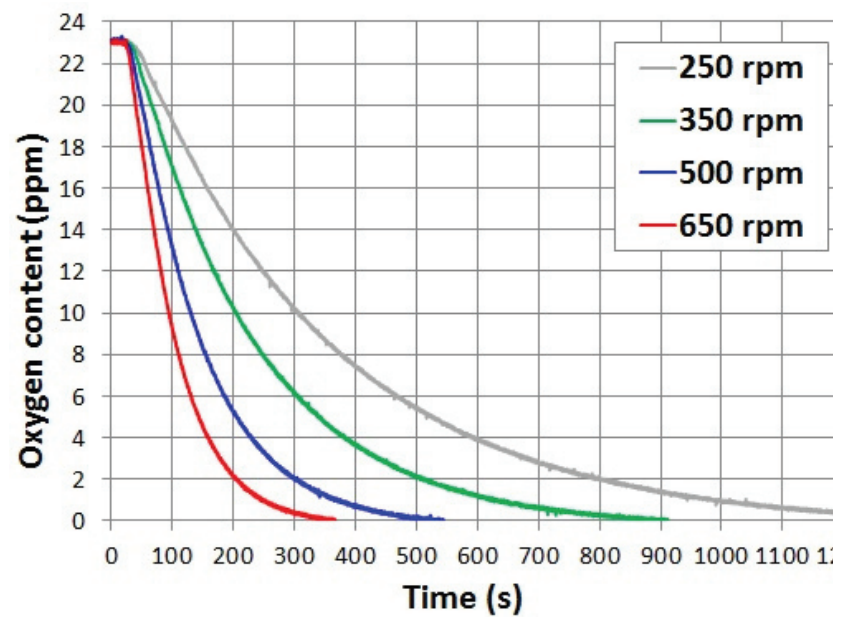

b) flow rate of Ar: $10.0 \mathrm{NI} \cdot \mathrm{min}^{-1}$

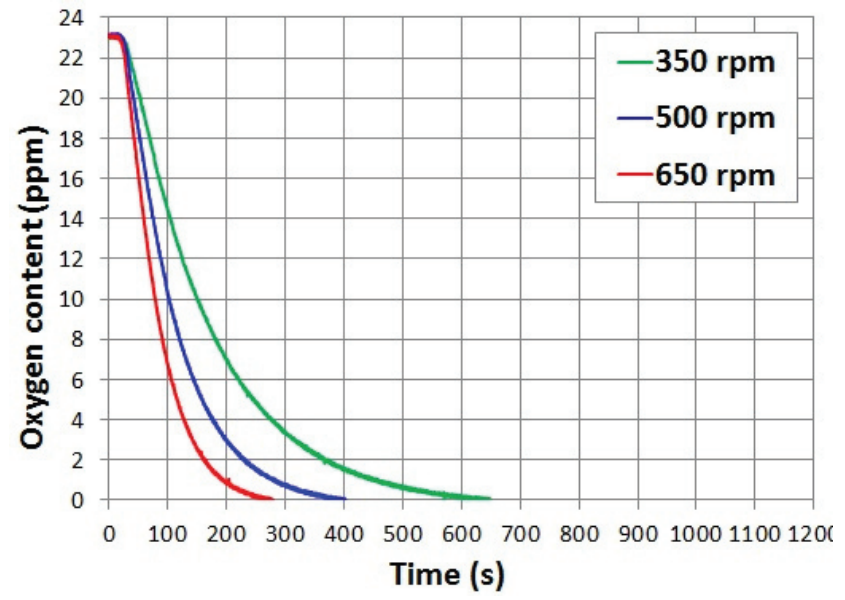

c) flow rate of $\mathrm{Ar}: 15.0 \mathrm{NI} \cdot \mathrm{min}^{-1}$

Figure 4 Change in the oxygen content at a different flow rate of Ar and rotary speeds in the range of $350 \mathrm{rpm}$ to $650 \mathrm{rpm}$

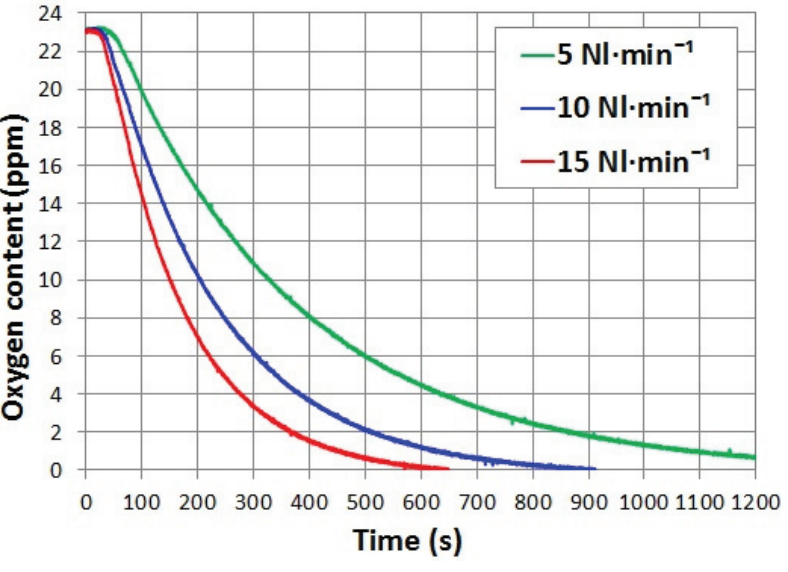

a) rotary impeller speeds: $350 \mathrm{rpm}$

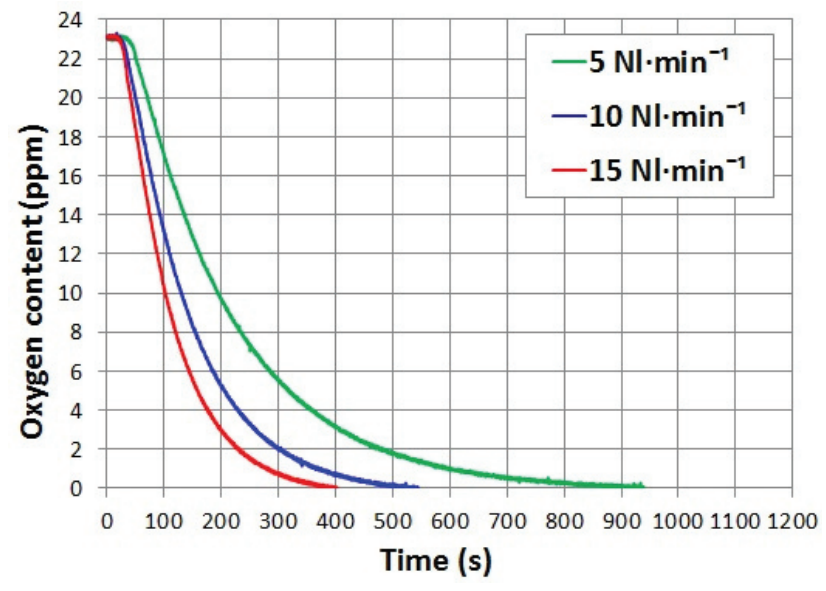

b) rotary impeller speeds: $500 \mathrm{rpm}$

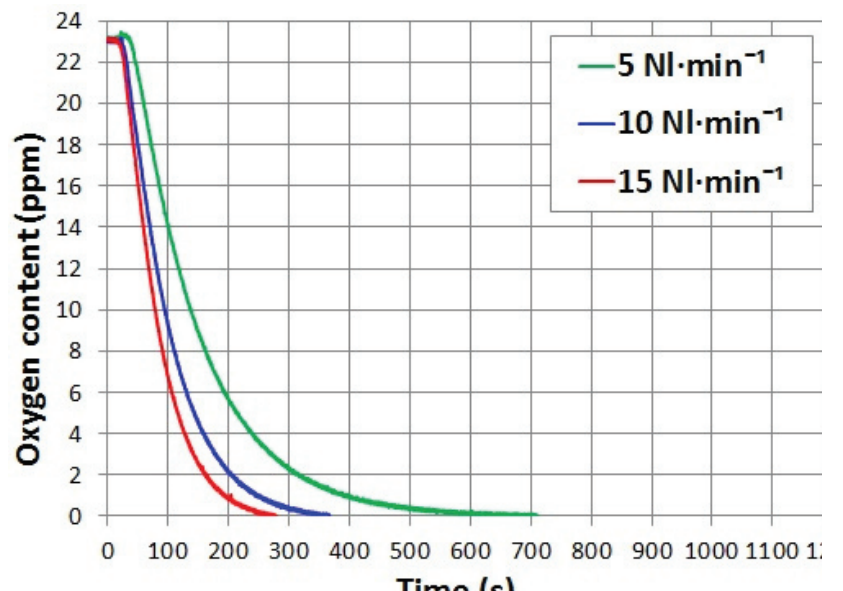

Time (s)

c) rotary impeller speeds: $650 \mathrm{rpm}$

Figure 5 Change in the oxygen content at different rotary impeller speeds and Ar flows in the range from $5 \mathrm{NI} \cdot \mathrm{min}^{-1}$ to $15 \mathrm{NI} \cdot \mathrm{min}^{-1}$ 


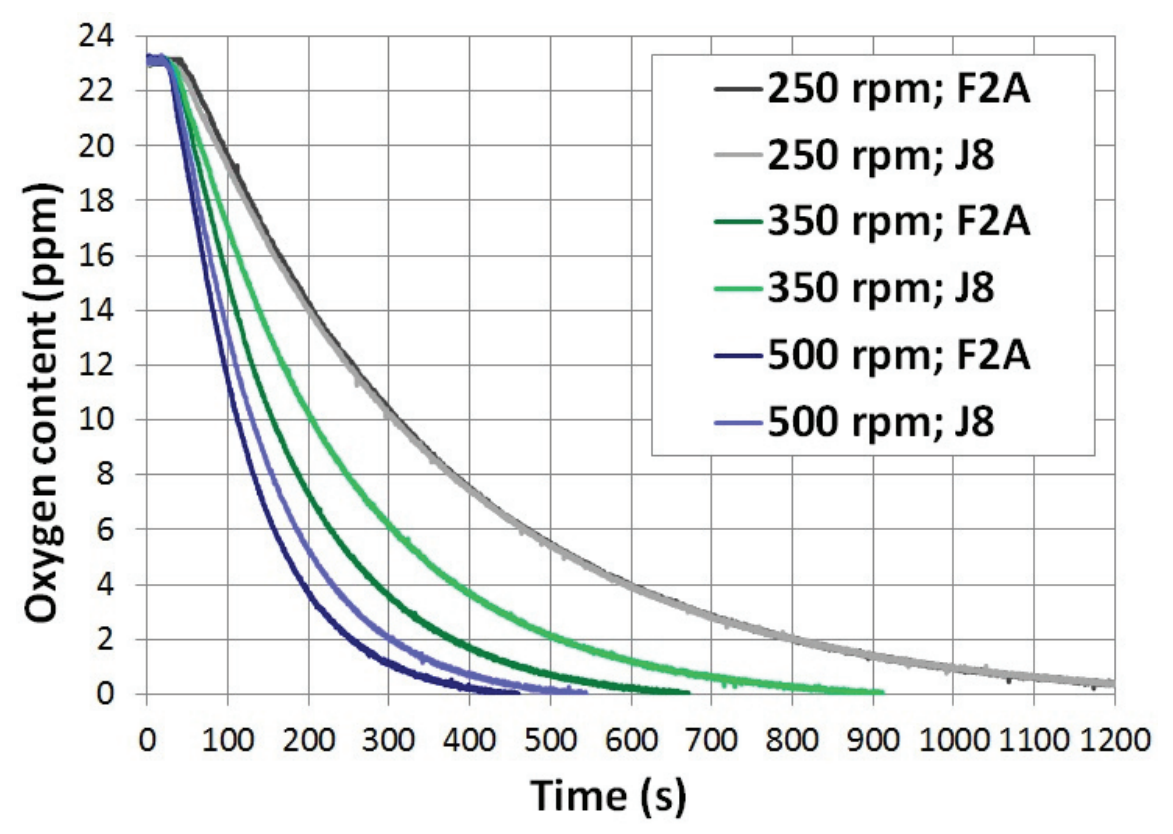

Figure 6 Influence of the variant of impeller: J8, F2A

During the experiments, photos of the bath behaviour inside the model were taken, from which the fluid flow and the amount and distribution of inert gas bubbles could be evaluated. In these photos, the effect of increasing rotary speeds ranging from 350 to $650 \mathrm{rpm}$ is evident, with the more intense distribution of bubbles throughout the refining ladle volume, as well as a higher level of bath surface ripple. For illustration, photos are shown at rotary speeds of 350,500 and $650 \mathrm{rpm}$ and at a flow rate of inert gas of $10 \mathrm{Nl} \cdot \mathrm{min}^{-1}$ (see Figure 7).

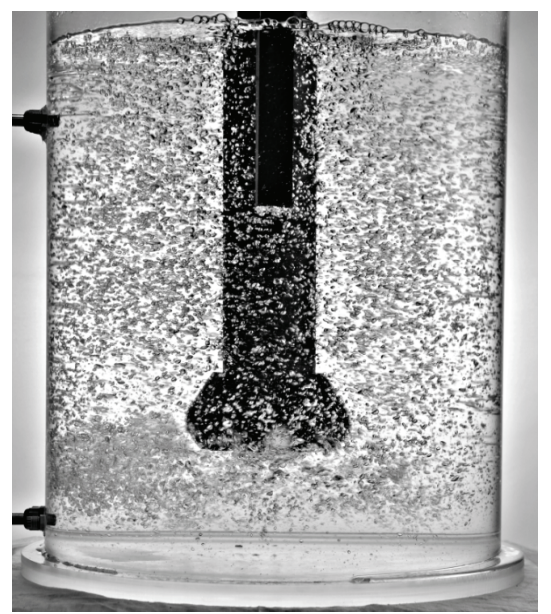

a) rotary impeller speed: $350 \mathrm{rpm}$

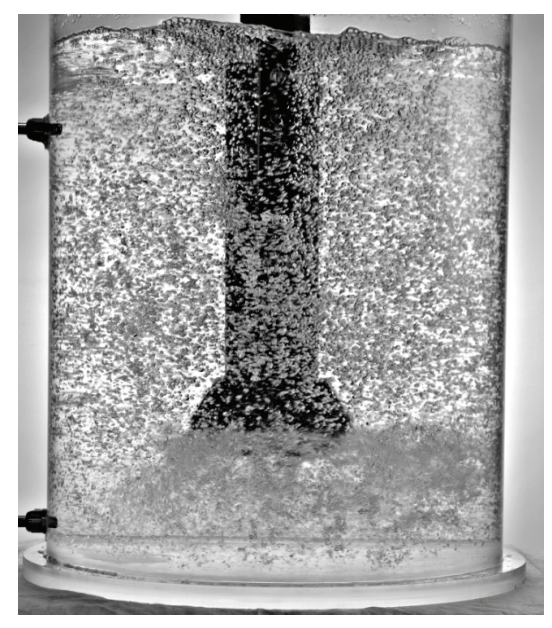

b) rotary impeller speed: $500 \mathrm{rpm}$

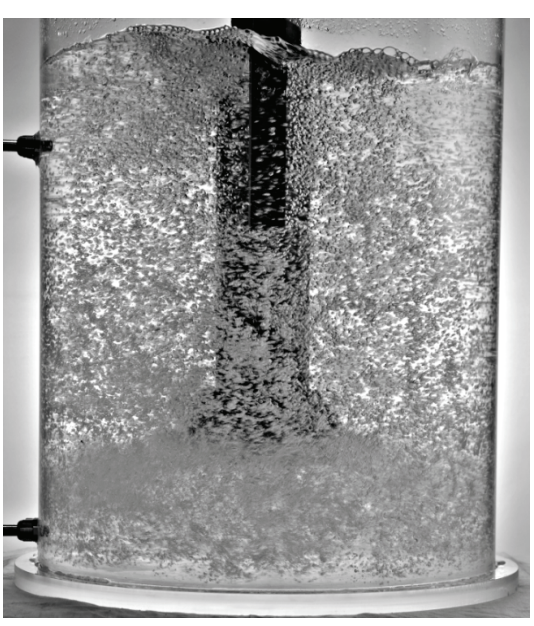

c) rotary impeller speed: $650 \mathrm{rpm}$

Figure 7 Example of the internal flow character, behaviour and distribution of the generated blown Ar bubbles and flow rate of $\mathrm{Ar} 10 \mathrm{NI} \cdot \mathrm{min}^{-1}$

The results obtained were also compared based on the time to reach the dimensionless concentration of 0.5 and 0.1 (see Figure 8 a Figure 9). The times $\boldsymbol{\tau}_{0.5}$ and $\boldsymbol{\tau}_{0.1}$ under which the oxygen concentration in the bath was reduced, were compared at $50 \%$ and $90 \%$ respectively, in which the so-called dimensionless 
concentrations $C_{x}=0.5$ a $C_{x}=0.1$ are achieved. These parameters can characterise decrease of the rate of dissolved oxygen in the bath.

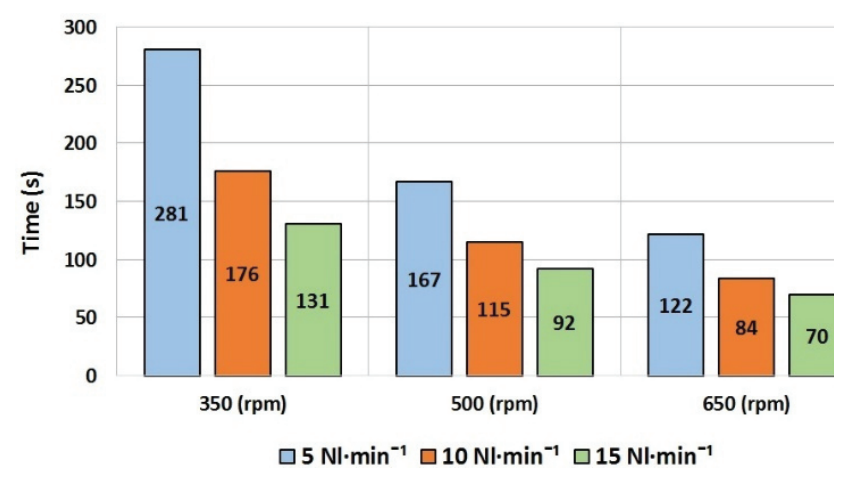

a) $\boldsymbol{\tau}_{0.5}$

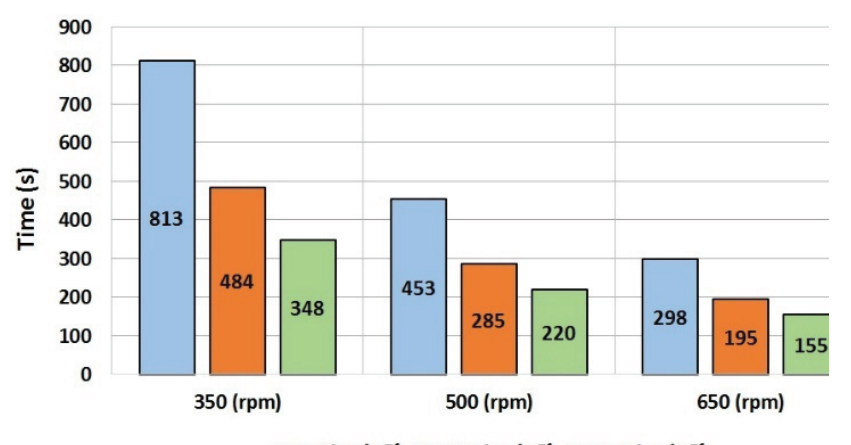

$\square 5 \mathrm{NI} \cdot \mathrm{min}^{-1} \square 10 \mathrm{NI} \cdot \mathrm{min}^{-1} \square 15 \mathrm{NI} \cdot \mathrm{min}^{-1}$

b) $\tau_{0.1}$

Figure 8 Comparison of the influence of the volume flow rate of argon and the impeller variant $\mathrm{J} 8$ rotary speed

The greatest influence on the reduction of oxygen concentration has impeller speed and volume flow rate. From Figure 8 we can confirm the conclusions set out in the previous section, analyses of experiments. Increasing the rotation speeds and increasing the volume flow rate of argon flow instantly reduces the oxygen concentration, same in time $\boldsymbol{\tau}_{0.5}$, and also in time $\boldsymbol{\tau}_{0.1}$.

The graphs in Figure 9 show the efficiency of the F2A impeller compared to the J8 impeller. At impeller speed of $250 \mathrm{rpm}$ the efficiency is the same for both variants. When the rotary speeds are increased to $350 \mathrm{rpm}$, the F2A impeller produces better results.

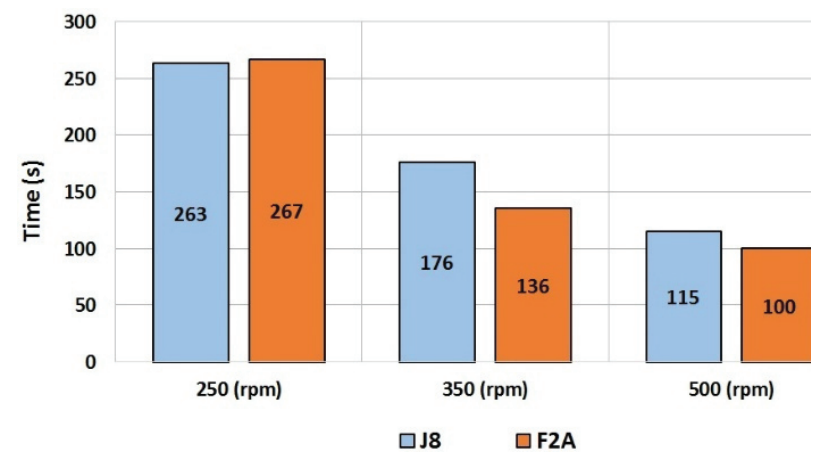

a) $\boldsymbol{\tau}_{0.5}$

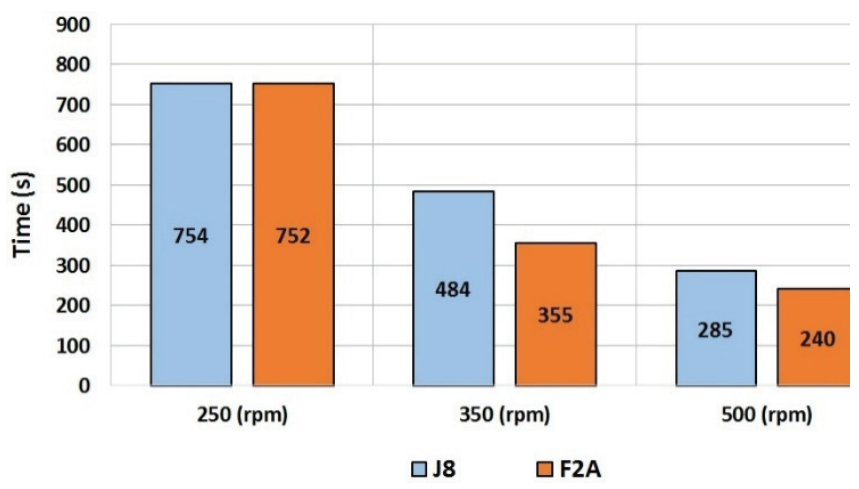

b) $\boldsymbol{\tau}_{0.1}$

Figure 9 Comparison of the influence of the impeller variant with the volume flow rate of argon $10 \mathrm{NI} \cdot \mathrm{min}^{-1}$

\section{CONCLUSIONS}

Experiments were conducted under laboratory conditions to determine and evaluate the effect of each parameter on the efficiency of the melt refining process. The ability to influence the efficiency of the process was compared for individual parameters. 
The evaluation of the experiments was carried out in three phases. In the first phase, visualisation photos were taken, where the size of bubbles and the distribution of these bubbles into the volume of the refining ladle were studied. During the experiments, the oxygen concentration in the bath was obtained and recorded and used in the graphs. In the last evaluation phase, the results were compared on the basis of the time of reaching a certain concentration in the bath (in this case 0.5 and 0.1 ).

From the results of the physical modelling we can see that the used optical fluorescence probes allow the correct measurement of the evolution of reduction of the oxygen content in water. Based on a series of experiments, it was proven that the rotary impeller speeds and the volume flow rate of the refining gas have a significant impact on the process of decreasing the oxygen content in water.

\section{ACKNOWLEDGEMENTS}

The work was created under the support of the Czech Ministry of Industry and Trade within the frame of the programme TRIO within the solution of the project reg. No. FV10080 "Research and Development of Advanced Refining Technologies of Aluminum Melts for Increase in Product Quality."

\section{REFERENCES}

[1] MICHALEK, K. Using of Physical and Numerical Modelling to Optimize Metallurgical Processes (Využití fyzikálního a numerického modelováni pro optimalizaci metalurgických procesů.). 1st edition. Ostrava: VŠBTechnical University of Ostrava. 2001. 125 p. ISBN 80-7078-861-5 (in Czech).

[2] SATERNUS, M. Rafinacja aluminum i jego stopów przez przedmuchiwanie argonem. Gliwice: Wydawnictwo Politechniky Ślaskej. 2011. 167 p. ISBN 978-83-7335-892-8 (in Polish).

[3] MICHALEK, K., TKADLEČKOVÁ, M., SOCHA, L., GRYC, K., SATERNUS, M., PIEPRZYCA, J. and MERDER, T. Physical modelling of degassing process by blowing of inert gas. Arch. Metall. Mater. 2018. vol. 63, no. 2, pp. 987-992. 